The Journal of

Thoracic and

Cardiovascular

Surgery

Vol 127, No. 6, June 2004

\title{
Coronary sinus retroperfusion: Can forward progress still be achieved by using a backward technique?
}

Harold L. Lazar, MD

See related article on page 1703.
From the Department of Cardiothoracic Surgery, the Boston University School of Medicine, and the Boston Medical Center, Boston, Mass.

Received for publication Feb 11, 2004; revisions received Feb 13, 2004; accepted for publication Feb 25, 2004

Address for reprints: Harold L. Lazar, MD, Department of Cardiothoracic Surgery, Boston Medical Center, 88 East Newton St, Boston, MA 02118 (E-mail: harold.lazar@ bmc.org).

J Thorac Cardiovasc Surg 2004;127: $1549-52$

$0022-5223 / \$ 30.00$

Copyright () 2004 by The American Association for Thoracic Surgery

doi:10.1016/j.jtcvs.2004.02.010

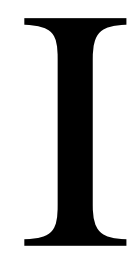

$\mathrm{n}$ this month's edition of the Journal, Syeda and colleagues ${ }^{1}$ report the results of a meta-analysis performed on randomized experimental trials to assess the efficacy of coronary sinus retroperfusion by using intermittent coronary sinus occlusion (ICSO) and synchronized retroperfusion (SRP) to salvage acutely ischemic myocardium.

In the ICSO technique a balloon-tipped catheter is positioned just beyond the orifice of the coronary sinus, similar to the placement of a retrograde coronary sinus cardioplegia catheter. The catheter is connected to a pneumatic pump that automatically inflates and deflates the balloon according to a preset cycle. A cycle of 10 seconds of inflation and 4 seconds of deflation was found to be the optimal period to limit the increase of pressure in the coronary sinus. This allows for sufficient drainage of coronary venous blood and avoids the complications of hemorrhage, edema, thrombosis, and arrhythmias observed with prolonged increase of coronary sinus pressure. This ability to limit peak coronary sinus pressure led to the term pressure-controlled intermittent coronary sinus occlusion (PICSO). The sudden occlusion of a coronary artery results in a significant decrease in coronary sinus pressure. By increasing coronary sinus pressure, PICSO redistributes coronary venous flow to jeopardized areas of the myocardium distal to an arterial occlusion. The intermittent inflation-deflation cycle also enhances the washout of toxic metabolites that form during periods of coronary occlusion and ischemia.

In contrast to PICSO, which displaces existing coronary venous blood, SRP actively pumps arterial blood retrograde through the coronary sinus. In this technique a catheter is placed in the femoral artery, and arterial blood is withdrawn and pumped into the coronary venous system during diastole through a catheter positioned into the coronary sinus. The meta-analysis by Syeda and colleagues ${ }^{1}$ of 7 experimental studies in which PICSO was performed during an acute coronary occlusion revealed a $29 \%$ reduction in infarct size $(P<.001)$, which increased to $39 \%$ when PICSO was combined with SRP. Our experimental studies, performed in a porcine model of acute coronary occlusion with reperfusion on cardiopulmonary bypass and cardioplegic arrest similar to urgent-emergency coronary artery bypass graft (CABG) surgery, support these favorable effects of PICSO in salvaging ischemic myocardium. PICSO enhanced the distribution of antegrade cardioplegia, ${ }^{2}$ improved regional wall motion and global left ventricular function, ${ }^{3}$ decreased tissue acidosis, ${ }^{2,3}$ and decreased infarct size. ${ }^{4}$ When combined with percutaneous bypass $^{5}$ and intra-aortic balloon pump (IABP) support ${ }^{6}$ in the same model, PICSO resulted in more complete reversal of ischemic damage than was observed from each individual modality alone. Mohl and coworkers ${ }^{7}$ showed that PICSO could be used clinically when they applied this technique in 15 patients undergoing multivessel CABG for 60 minutes during the reperfusion period. PICSO resulted in a significant improvement in regional wall motion in segments that were previously 
hypokinetic, as assessed by means of intraoperative 2-dimensional echocardiography.

The beneficial effects of PICSO and SRP in these experimental studies prompted a renewed interest in coronary retroperfusion by both cardiologists and surgeons as a means to limit myocardial damage during acute coronary syndromes. Patients with an acute myocardial infarction (MI) or unstable angina arriving at a community hospital could have the PICSO catheter inserted percutaneously through the internal jugular vein and guided by means of fluoroscopy into the coronary sinus. The initiation of PICSO would provide some blood flow to the ischemic area of the myocardium during transport to a tertiary referral center with a cardiac catheterization laboratory. Catheterization could then be performed to assess the coronary anatomy. If a percutaneous procedure was to be performed, PICSO could be used to administer antiarrhythmic agents, oxygenfree radical scavengers, essential substrates, and thrombolytic agents, which were found to be more effective when delivered retrograde to jeopardized myocardium. ${ }^{8-11}$ If surgical revascularization was necessary, the PICSO catheter could be used during the period of cardioplegic arrest to administer retrograde cardioplegia or improve the distribution of antegrade cardioplegia. PICSO also could be used to stabilize patients in the catheterization laboratory after an abrupt coronary occlusion during an attempted percutaneous transluminal coronary angioplasty. The IABP can help to support the systemic circulation and unload the ventricle but is limited in its ability to directly augment coronary blood flow. PICSO can provide blood flow to areas of jeopardized myocardium while the patient is transferred to the operating room for emergency CABG surgery.

Despite these potentially clinically important applications of PICSO and SRP, the only form of retroperfusion performed by cardiac surgeons today is retrograde coronary sinus cardioplegia. Why have these other techniques failed to emerge as useful therapeutic interventions for cardiologists and surgeons? SRP proved to be a cumbersome and potentially dangerous technique in clinical practice. It required catheterization of the femoral artery, which is a problem for patients with peripheral vascular disease. The pneumatic pump designed for PICSO required only a simple bellows mechanism. A more sophisticated pumping device was required for SRP, where higher coronary sinus pressures were more likely to be encountered because of the direct infusion of blood into the coronary sinus during diastole. Flow rates were critical with SRP and had to be continuously monitored. Coronary sinus flow rates of less than $50 \mathrm{~mL} / \mathrm{min}$ resulted in poor results, yet flow rates of greater than $200 \mathrm{~mL} / \mathrm{min}$ might result in permanent damage to the coronary sinus with thrombosis and ultimately stenosis and chronic myocardial edema. Although most studies with SRP concentrated on treating left anterior descending coronary artery occlusions, the effects of SRP on right coronary and circumflex coronary artery occlusions were not as well documented.

PICSO was a much easier technique to institute because it did not require catheterization of the femoral artery and results in only transient increases in coronary sinus pressures, which were well tolerated. This technique did not require the constant monitoring of inflation and deflation seen with SRP. Why then was PICSO excluded from the treatment of acute coronary syndromes? Although the mid1980s saw a renewed interest in retrograde coronary sinus perfusion as a method to salvage acutely ischemic myocardium, it also marked the introduction of antegrade percutaneous techniques to directly restore coronary blood beyond an obstructing lesion. With the advancement in methodology of angioplasty catheters, the use of bailout wires, the development of glycoprotein 11b/IIIa receptor inhibitors, and ultimately the introduction of stents, the interventional cardiologist now had the means to directly augment coronary artery blood flow. PICSO and SRP were now viewed as palliative and temporizing techniques, as opposed to therapeutic angioplasty, stents, and thrombolytics, which by themselves could permanently revascularize the ischemic myocardium. With improvements in these techniques came a significant increase in procedural success and a concomitant reduction in complications, especially in the need for emergency CABG. The reported rate of emergency CABG for a failed percutaneous transluminal coronary angioplasty is now less than $0.4 \%,{ }^{12}$ and this was to have been a primary indication for PICSO therapy. The introduction of stents further diminished the potential role of PICSO as a support device after a failed angioplasty. In our own institution, the incidence of emergency CABG after a failed angioplasty in the stent era decreased to less than $1 \% .{ }^{13}$ More importantly, there was a decrease in the incidence of abrupt coronary occlusions as the primary indication for emergency operations from $76 \%$ to $11 \%(P<.0001)$. With stents now available, the culprit vessel could remain open to allow some antegrade flow to the area of jeopardized myocardium, and the incidence of perioperative MIs decreased from 50\% to $19 \%(P<.02)$. CABG surgery could now be done in a less urgent manner because the patients were now more hemodynamically stable. This had a significant effect on mortality for emergency CABG procedures after a failed angioplasty, which decreased from $17.6 \%$ to $0 \%(P<.03)$ in our own series. ${ }^{13}$

With the continued improvement of retrograde techniques, the selection criteria for patients and lesions amenable to percutaneous procedures broadened to include high-risk patients with acute coronary syndromes and even cardiogenic shock. Despite this, the need for CABG surgery and possible PICSO intervention in these patients was further reduced and is now as low as $0.2 \% .{ }^{14}$ In addition to the 
increased success with antegrade techniques, it was now possible to perform these interventions more rapidly because more community hospitals began to open catheterization laboratories. Hence ischemic times were now reduced because patients were transferred to tertiary referral hospitals less frequently.

The success of antegrade catheter technology prompted industry to turn away from developing the methodology necessary for PICSO. New PICSO catheters had to be developed that could be safely inflated and deflated in the coronary sinus 6 times per minute for possibly 24 to 48 hours. Faced with the choice of investing in the everexpanding, lucrative, therapeutic antegrade catheter market versus the low-volume clinically uncharted waters of temporizing and palliative PICSO therapy, the captains of industry chose the former, as did our cardiology colleagues.

Is there still a role for coronary sinus retroperfusion with PICSO in the current therapy for acute coronary syndromes and during cardiac surgery in our practices today? I believe that there is for patients with acute MIs and patients undergoing beating-heart, off-pump CABG surgery. PICSO could be a useful technique to salvage myocardium after acute infarction. Despite the success of thrombolytic therapy and acute angioplasty procedures, it is estimated that only a third of patients presenting with an acute MI are eligible for thrombolytic therapy. ${ }^{15}$ These patients will require transport to the catheterization laboratory from either community hospitals or their own facility where emergency percutaneous angioplasty or CABG might be required. It has been documented that the interval from the presentation to the emergency department to the actual angioplasty (down to balloon time) is an independent predictor of 30-day mortality. ${ }^{16}$ PICSO might play an important role in preserving myocardial viability and as a route to administer antiarrhythmics, thrombolytics, substrates, oxygen-free radical scavengers, and inotropics for more effective distribution to jeopardized myocardium. PICSO therapy is easy to initiate and does not require peripheral arterial catheterization so that patients with peripheral vascular disease can be included. With the ever-increasing experience of coronary sinus catheterization gained by electrophysiologists from ablation procedures and pacemaker insertions, as well as own experience with Heartport instrumentation, it is estimated that PICSO therapy could be instituted in as little as 5 minutes. Furthermore, studies by Faxon and colleagues ${ }^{17}$ showed that diastolic coronary sinus occlusion pressure correlated with left ventricular end-diastolic pressure. Hence PICSO might also be used to monitor left ventricular function during this critical period and avoid the extra time needed to insert a Swan-Ganz catheter. Although PICSO cannot independently support the systemic circulation, it might also be used to stabilize patients with unstable angina in the cardiac care unit who are unresponsive to medical management and are not candidates for IABP support. Unlike the IABP, PICSO is effective even in the presence of atrial and ventricular arrhythmias.

The second potential application for PICSO is as a cardioprotective technique during off-pump, beating-heart surgery. Retroperfusion with PICSO might avoid or decrease the amount of ischemia incurred during the time the coronary artery vessels are occluded. It is uncertain as to what the effect of tilting the heart in various positions will have on the ability to achieve coronary venous retroperfusion. Nevertheless, PICSO remains a potential technique to minimize ischemia during off-pump CABG surgery.

What will it take to introduce PICSO into clinical practice today? Industry must work with clinicians to develop catheters that will safely inflate and deflate in the coronary sinus for prolonged periods (24-48 hours). An easy way to start is to use the current catheters available for coronary sinus cardioplegia administration and make the necessary modifications to prevent premature rupture. The pneumatic pumps are already available and require no further alterations. Prospective and clinical studies will need to be designed comparing not only survival, enzyme leaks, and electrocardiographic changes but also more sophisticated diagnostic techniques, such as echocardiography, nuclear magnetic resonance, and positron emission tomography scanning to more accurately document and detect quantitative changes in regional function and infarct size.

PICSO technology can be easily developed, and definitive clinical studies can be performed to reestablish the potential role for coronary sinus retroperfusion in our practice today. In our current environment of constant evolving technology, forward progress might still be achieved by using a backward technique.

\section{References}

1. Syeda B, Schukro C, Heinze G, Modaressi K, Glogar D, Maurer G, et al. The salvage potential of coronary sinus interventions: meta-analysis and pathophysiologic consequences. J Thorac Cardiovasc Surg. 2004; 127:1703-12.

2. Lazar HL, Khoury T, Rivers S. Improved distribution of cardioplegia with pressure-controlled intermittent coronary sinus occlusion. Ann Thorac Surg. 1988;46:202-7.

3. Lazar HL, Rajaii A, Roberts AJ. Reversal of reperfusion injury after ischemic arrest with pressure-controlled intermittent coronary sinus occlusion. J Thorac Cardiovasc Surg. 1988;95:637-42.

4. Lazar HL, Haan CK, Yang X, Rivers S, Bernard S, Shemin RJ. Reduction of infarct size with coronary venous retroperfusion. Circulation. 1992;86(suppl II):II352-7.

5. Lazar HL, Treanor P, Rivers S, Bernard S, Shemin RJ. Combining percutaneous bypass with coronary retroperfusion limits myocardial necrosis. Ann Thorac Surg. 1995;59:373-8.

6. Lazar HL, Yang XM, Rivers S, Treanor P, Bernard S, Shemin RJ. Retroperfusion and balloon support to improve coronary revascularization. J Cardiovasc Surg. 1992;33:538-44.

7. Mohl W, Simon P, Neumann F, Schreiner W, Punzengruber C. Clinical evaluation of pressure-controlled intermittent coronary sinus occlusions: randomized trial during coronary artery surgery. Ann Thorac Surg. 1988;46:192-201.

8. Hatori N, Miyasaki A, Tadokoro H. Beneficial effects of coronary 
venous retroinfusion of superoxide dismutase and catalase on reperfusion arrhythmias, myocardial function and infarct size in dogs. J Cardiovasc Pharmacol. 1989;14:396-404.

9. Karagueuzian HS, Ohta M, Drury SK. Coronary venous retroinfusion of procainamide: a new approach for the management of spontaneous and inducible sustained ventricular tachycardia during myocardial infarction. J Am Coll Cardiol. 1986;7:551-63.

10. Kobayashi S, Tadokoro $\mathrm{H}$, Wakida $\mathrm{Y}$, et al. Coronary venous retroinfusion of deferoxamine reduces infarct size in pigs. $J$ Am Coll Cardiol. 1991;18:621-7.

11. Miyazaki A, Tadokoro H, Drury JK, Ryden L, Haendchen RV, Corday E. Retrograde coronary venous administration of recombinant tissuetype plasminogen activator: a unique and effective approach to coronary artery thrombolysis. J Am Coll Cardiol. 1991;18:613-20.

12. Williams DO, Holubkov R, Yeh W, et al. Percutaneous coronary intervention in the current era compared with 1985-1986: the National Heart, Lung and Blood Institute Registries. Circulation. 2000;102:2945-51.

13. Lazar HL, Bao Y, Lancaster D, Shapira OM, Aldea GS, Shemin RJ.
Favorable impact of stents after emergent coronary artery bypass for failed angioplasty. Ann Thorac Surg. 1999;68:1644-7.

14. Suryapranata H, Vanthof AW, Hooorntje JC, de Boer MJ, Zoslstra F. Randomized comparison of coronary stenting with balloon angioplasty in selected patients with acute myocardial infarction. Circulation. 1998;97:2502-5.

15. Barron HV, Rundle A, Gurwitz J. Tiefenbrunn A. Reperfusion therapy for acute myocardial infarction: observations from the National Registry of Myocardial Infarction 2. Cardiol Rev. 1999;7:156-60.

16. Berger PB, Ellis SG, Holmes DR Jr, et al. Relationship between delay in performing direct coronary angioplasty and early clinical outcome in patients with acute myocardial infarction: results from the global use of strategies to open occluded arteries in acute coronary syndromes (GUSTO-IIb) trial. Circulation. 1999;100:14-20.

17. Faxon DP, Jacobs AK, McSweeney SM. Coronary sinus assessment of left ventricular pressure in man. In: Mohl W, Wolner E, Glogar D, editors. The coronary sinus. New York: Springer-Verlag; 1984. p. 424-9.

\section{The Journal of Thoracic and Cardiovascular Surgery Conflict of Interest Policy}

To assure fairness to authors submitting work for consideration in The Journal of Thoracic and Cardiovascular Surgery, a mechanism exists for managing conflicts of interest. The editor and each of the section editors complete a "Conflict of Interest" form that identifies any and all relationships with commercial and other academic entities. When the editor has a potential conflict because of a relationship with another entity or author, the editor appoints an alternate editor from among the section editors or editorial board members who assumes the entire responsibility for final decisions on the manuscript in question. The editor does not read the reviews that are submitted nor engage in discussing the manuscript prior to the final decision. When the conflict of interest involves a section editor, a "guest section editor" is appointed who fills the role normally played by the conflicted section editor. All members of the editorial board and reviewers are asked to indicate any conflict of interest when they agree to review a manuscript. 